\title{
Health Care Providers' Awareness Regarding Quality Management System and Its Relation to Patient Satisfaction
}

\author{
Samia Abdallah Adam*, Hanaa Mohamed Abd Rabou*, Amna El-sayed Abd el-ghany \\ Afify** \\ * Nursing Administration Department - Faculty of Nursing-Ain Shams University \\ ** B.Sc. Nursing
}

\begin{abstract}
Introduction: quality is emerging as a dominant and complex theme in today's competitive health care environment; it plays an important role in patients' choice of hospital. Quality of care is partly a function of the need for care and includes patients' satisfaction which is a function consistent with scientific knowledge and generally accepted professional standards. Aim: the present study aimed to assessing health care providers' awareness regarding quality management system and it's relation to patient satisfaction through assessing the awareness level of health care providers regarding quality management system, assessing the level of patient satisfaction regarding quality of health care provided, and finding out the relationship between health care providers' awareness and patient satisfaction. Research Design: A descriptive, correlational design was used. Setting:. This study was conducted at 12 Benha Family Health Centers, 120 nurses, 120 Physicians, and 300 patient from this twelve centers were included in the study. Tools of data collection: two different tools were used namely questionnaire for health care providers' awareness and patients satisfaction questionnaire. Results: The total healthcare providers' awareness had increased due to higher scores in constant and quality unit parameters at the studied centers. as well as There was a higher total satisfaction scores for patients due to higher percentages in their ages and medical services provided to them., also As the increasing of awareness regarding quality management system it had an impact on increasing the quality of health care services resulting in increasing of patients' satisfaction. As the decreasing of awareness regarding quality management system had an impact on decreasing the quality of health care services resulting in decreasing of patient satisfaction. Conclusion: there was a strong positive correlation between health care providers' awareness and patients' satisfaction: Recommendation: Improving the quality of health care provided to patients in the studied centers, suggestions and complaints of patients should be Taken into consideration to improve quality services and increase pt satisfaction. Keywords: Quality management system, health care providers, awareness and patients' satisfaction..
\end{abstract}

Key words: Health Care Providers', Quality Management System, Patient Satisfaction.

Introduction

Today, quality is emerging as a dominant and complex theme in today's competitive health care environment; it plays an important role in patients' choice of hospital (Legido, 2008). Health care agencies are under pressure to do more with less 
competition among health care firms is growing stronger, and patients became more aware about their rights (Lippincott \& Wilkins, 2011). Quality of care is partly a function of the need for care and includes patients' satisfaction which is a function consistent with scientific knowledge and generally accepted professional standards (Waltz, 2010).

The concern for high quality health care dates back to the 5 century (B.C), when Hippocrates established a code of medical ethics, obliging future doctors to swear "never to do harm to any one" (Wensley, $2001 \&$ Peters 2005). In the light of quality definition, quality is a difficult concept to define with any precision, the most fundamental definition of a quality product is one that meets the expectation of the customer (Loraine, 2011). Quality also means the highest degree of excellence of the total features and characteristics of the product or service that satisfies stated or implied needs (Jack \& Larry, 2004).

The Jjoint Commission on Accreditation of Health Care Organization (JACHO) define quality as a measure of how closely a service confirms to specified standard, and the degree to which patient care services increase the probability of desired patient outcomes and reduce the probability of undesired patient outcomes (JACHO, 2005).

The purpose of quality management system is to ensure that health care providers learn and follow standards which are thought to ensure quality care to patients, and that management at different levels monitor, supervise and support these actions (Alserouri \& Alsofeani, 2015). Health care providers are the critical persons which measuring and managing care outcomes ; sees best the global and specific issues and intricacies of measures and measurement, most likely going to collect original quality data (Fetter, 2007).
Quality awareness programs help to prepare people in all functions and at all levels of organization to become effective participants in continuous improvement (Sylvester \& Fathy, 2013). Ignoring or misunderstanding of patient expectations from health providers is equivalent to sending them to the competition with patients. Furthermore, if the organization (administrators, nurses and physicians) fail to be sufficiently aware to what patients really expect, this leads to depressing of any initiative or improvement intention. To avoid this problem all health care providers need to really determine patients' expectations (Swayne, 2014).

\section{Significance of the study:}

Providing health care with high quality for patients become the focus of health care providers in the family health centers in Egypt. By working in Benha family health centers, the researcher observed the dissatisfaction of patients regarding the level of the quality of health care provided, Where it appeared through the persistent complaints of patients. At the same time, the researcher observed that the health care providers do not have the sufficient awareness regarding the quality management system that may affect the quality of health care provided. Therefore, the researcher conducted this study to find the relationship between health care providers' awareness regarding quality management system and level of patient's satisfaction.

\section{Aim of the Study:}

This Study aimed at assessing health care providers' awareness regarding quality management system and it's relation to patient satisfaction through:-

- Assessing the awareness level of health care providers regarding quality management system. 
- Assessing the level of patient satisfaction regarding quality of health care provided.

- $\quad$ Finding out the relationship between health care providers' awareness and patient satisfaction.

\section{Subjects and Methods:}

The research questions were:

- What is the level of health care providers' awareness regarding quality management system?

- What is the level of patient satisfaction regarding the quality of health care provided?

- Is there a relationship between health care providers' awareness and patient satisfaction?

The methodology of this study was portrayed under four main designs as follows:

I. Technical design.

II. Operational design.

III. Administrative design.

IV. Statistical design.

I. Technical Design:

The technical design for this study included research design, setting of the study, subjects and tools of data collection.

\section{Research design:}

Adescriptive, correlational design was used in this study.

\section{Setting:}

This study was conducted at Benha Family Health Centers (12 centers), which affiliated to Ministry of Health in Egypt. They are located in El-qualubia Governorate $\backslash$ Egypt, The total number of Benha family health centers are thirty one family health centers. Twenty-nine of these centers had accredited in 2005 and they are visited by quality committees from The Ministry of Health $(\mathrm{MOH})$ every two years, while the two remaining centers are not accredited till now.

Twelve centers were included in the study. The centers were randomly selected according to a stratified cluster sampling technique out of thirty one family health centers.

\section{The first group:- ( physicians group).}

After compensation of a non-response rate of about $15 \%$, the selected sample was 120 Physicians out of the total number of physicians in family health centers that were about 488 Physicians, statistical equation was used to select the required sample size in the study. The sample size was calculated to measure an expected rate of satisfactory awareness of $60 \%$ (as set by the Ministry of Health for accreditation) or higher, with a 95\% confidence level, and a $3 \%$ standard error, using the sample size equation for estimation of single proportion, with finite population correction (Kish \& Leslie, 1965). 2. The second group: - (Nurses
group).

After compensation of a non-response rate of about $15 \%$, the selected sample was 120 nurses out of the total number of nurses in family health centers that were about 462 Nurses, statistical equation was used to select the required sample size in the study. The 
sample size was calculated to measure an expected rate of satisfactory awareness of $60 \%$ (as set by the Ministry of Health for accreditation) or higher, with a $95 \%$ confidence level, and a 3\% standard error, using the sample size equation for estimation of single proportion, with finite population correction (Kish and Leslie, 1965).

After compensation of a non-response rate of about $15 \%$, the sample was 120 .

After using the stratified cluster sampling technique which results in selecting 12 family health centers, a simple random sample of 10 nurses were randomly selected from each of the 12 centers.

\section{The third group:- (patients group).}

Patients number from the family health centers was large and variable from one center to another, statistical equation was used to select the required sample size in the study. A stratified cluster sampling technique was used. From each of the 12 centers, 25 patients were randomly selected.

\section{Tools of data collection:}

Two different tools were used for data collection namely questionnaire for health care providers' awareness and patients satisfaction questionnaire:

First tool:- Awareness questionnaire sheet:- It was a structured questionnaire developed by Fathy (2013), and modified by the researcher. It was consisted of two parts:-

Part one:- included questions regarding socio-demographic data as: -

Family health center name, job, specialization, date of birth, years of experience, level of education, attending training about quality before.
Part two: - It aims to assess the health care providers' awareness level regarding quality management system; it was answered by both nurses and physicians. It consisted of ten elements and fifty-fives Subsequent items shown in the following table.

\section{Second tool:- Patient Satisfaction Questionnaire (Appendix II):-}

It was a structured questionnaire developed by the researcher after reviewing related literature \{ Egyptian $\mathrm{MOH}$ check list for estimating the level of patient satisfaction regarding quality of health care provided to patient July (2005) \& The Patient Satisfaction Questionnaire Short -Form (Marshall \& Rand,1994).

\section{This tool was consisted of two parts: -}

Part one: - It included questions regarding socio-demographic data as: - The family health center name, patient name, gender, age, marital status, the level of education, job.

Part two: - It concerned with the level of patient satisfaction regarding the quality of health care provided in Family health centers, it consisted of seven elements and eighty Subsequent items .

Tool validity: the tools were validated by jury members. The jury consists of seven professors and assistant professors experts with coefficient of agreement $98 \%$ for the awareness questionnaire sheet, and $90 \%$ for the patient satisfaction tool.

Tools reliability: Testing reliability of proposed tools was done by Cronbach's alpha test. The result were (0.613) for Awareness questionnaire, and (0.953) for patient satisfaction questionnaire. 


\section{Operational design:}

The operational design included preparatory phase, pilot study and field work.

\section{Preparatory phase:}

Field work for this study extended through the period from the beginning of (July 2016) to (September 2016).

It included reviewing of related literature, theoretical knowledge of various aspects of the study using books, articles, internet, periodicals and journals. Tools are adopted from Egyptian and Foreign references. The tool was developed in English language and then translated into Arabic and displayed this translation to the three members of the faculty of Alson, English Department, Ain-shams University to clarify whether the Arabic translation conveys the same meaning in the English language or not, The researcher made some modifications to the Arabic translation.

\section{Pilot study:}

A Pilot study was conducted on about $10 \%$ of the total subjects before performing the main study. They were selected randomly from the study subject to test the feasibility, practicability of the tools and clarity of the language of the questionnaires., 10 physicians, 10 nurses and 25 patient from each centers were included. It has also served in estimating the time needed for filling the form. It helped in identifying potential obstacles and problems that may be encountered during the period of data collection. It ranged between 25-30 minutes. This stage took 4 weeks. The sample of pilot study were excluded from the main study sample.

\section{Field work:}

The other side the situation was a little different for patients depending on their degree of education and awareness. Questionnaires were distributed to patients and explained to them. Initially the researcher found a lot of rejection and refused from some illiterate patients to participate in filling in the questionnaires because of their inability to read and write; so the researcher stayed with each illiterate patient individually trying to read and explain the items of questionnaire to them, and thus was answering all the points and the researcher was recorded their answer in its questionnaire according to his desire.

\section{Administrative design:}

An official permission obtained from the Dean of the Faculty of Nursing, AinShams University to the director of the study setting. It included the aim of the study and the expected benefits.

\section{Ethical considerations:}

Prior study conduction, formal approval obtained from the scientific research and ethical committee of the Faculty of Nursing, Ain-Shams University. The researcher meet the director of Benha family health centers to clarify the aim of the study and take their approval, the researcher also meet study subject to explain the purpose of the study and take their approval to participate on the study. The participants in the study assured complete confidentiality and anonymity of the data collected, and the data used only for the purpose of scientific research. The subject's right to withdraw from the study at any time was assured. The study procedures do not entail any harmful effects on participants. 
III. Statistical design:

Data entry and statistical analysis were done by using (SPSS) Version 18 statistical software package and Microsoft office excel for data handling and graphical presentation. Data were presented using descriptive statistics in the form of frequencies and percentages for qualitative variables. Means and standard deviation and range for quantitative variables. Student t-test $(\mathrm{t})$ was used for comparisons between twoindependent quantitative variables and ANOVA (F) test was also used for comparisons between more than two groups dependent quantitative variables. The correlation between health care providers' awareness and patient satisfaction variables scores was analyzed by Spearman's rank correlation coefficient. Statistical significance was considered at p-value $<0.05$ and highly significant at p-value $<0.01$. Linear regression model. Correlation Coefficient (r) test was used to test the closeness of association between two variables.

\section{Result:}

Part (I): Socio-demographic and characteristics of the study subjects

Table (1): Socio-demographic and job characteristics of studied nurses $(n=120)$

\begin{tabular}{|c|c|c|}
\hline Socio-demographic and job characteristics & No. & $\%$ \\
\hline \multicolumn{3}{|l|}{ Age in years: } \\
\hline$<30$ & 51 & 42.5 \\
\hline $30-$ & 69 & 57.5 \\
\hline Range & \multicolumn{2}{|c|}{$24.0-59.0$} \\
\hline Mean \pm SD & \multicolumn{2}{|c|}{$32.8 \pm 6.9$} \\
\hline Median & \multicolumn{2}{|c|}{31.00} \\
\hline \multicolumn{3}{|l|}{ Experience years: } \\
\hline$<10$ & 71 & 59.2 \\
\hline $10-$ & 49 & 40.8 \\
\hline Range & \multicolumn{2}{|c|}{$1.0-40.0$} \\
\hline Mean \pm SD & \multicolumn{2}{|c|}{$10.4 \pm 7.2$} \\
\hline Median & \multicolumn{2}{|c|}{8.00} \\
\hline \multicolumn{3}{|l|}{ Nursing qualification: } \\
\hline Diploma & 100 & 83.3 \\
\hline Bachelor & 20 & 16.7 \\
\hline \multicolumn{3}{|l|}{ Job position: } \\
\hline Staff nurse & 97 & 80.8 \\
\hline Nurse specialist & 23 & 19.2 \\
\hline \multicolumn{3}{|l|}{ Specialty: } \\
\hline General & 56 & 46.7 \\
\hline Medical & 6 & 5.0 \\
\hline Surgical & 23 & 19.2 \\
\hline Pediatric & 7 & 5.8 \\
\hline Auxiliary & 28 & 23.3 \\
\hline Attended training courses in quality & 95 & 79.2 \\
\hline Had administrative job & 47 & 39.2 \\
\hline Shared in quality programs & 80 & 66.7 \\
\hline
\end{tabular}


Table (1) shows that more than half (57.5\%) of nurses' had age less than 30 years, and $(59.2 \%)$ of them had experience more than 10 years. As far as nurse's qualification, the table shows that the majority $(83.3 \%)$ of nurses had diploma. And most of nurses $(79.2 \%)$ were attending training courses in quality. As well as two-thirds of nurses $(66.7 \%)$ were sharing in quality programs.

Table (4): Distribution of studied patients by centers $(n=300)$

\begin{tabular}{|l|c|c|}
\hline \multicolumn{1}{|c|}{ Centers } & Frequency & Percent \\
\hline Meniat el-sebaa & & 8.3 \\
Ganagara & 25 & 8.3 \\
Alramla & 25 & 8.3 \\
Batmada & 25 & 8.3 \\
Kafr Atalla & 25 & 8.3 \\
Marsaf & 25 & 8.3 \\
Naqbas & 25 & 8.3 \\
Basta & 25 & 8.3 \\
Lafr elarab & 25 & 8.3 \\
Alshamout & 25 & 8.3 \\
Magoul & 25 & 8.3 \\
Meet alattar & 25 & \\
\hline
\end{tabular}

Table (4) shows that the study sample was conducted on 300 patients at 12 family health centers. Also it shows that the represented numbers of patients for each center was 25 patients. studied centers

Part (II): Awareness of healthcare providers regarding quality management system in the

Table (5): Awareness of nurses and physicians regarding quality definition and consequences in the study sample

\begin{tabular}{|c|c|c|c|c|c|c|}
\hline \multirow[t]{2}{*}{ Quality management systems } & \multicolumn{2}{|c|}{$\begin{array}{l}\text { Nurses } \\
(\mathrm{n}=120)\end{array}$} & \multicolumn{2}{|c|}{$\begin{array}{l}\text { Physicians } \\
(\mathrm{n}=120)\end{array}$} & \multirow[t]{2}{*}{$X^{2}$} & \multirow[t]{2}{*}{$\mathrm{p}$} \\
\hline & No. & $\%$ & No. & $\%$ & & \\
\hline $\begin{array}{l}\text { Definition: } \\
\text { - Performing something correctly from the first time } \\
\text { and finding a chance to improve it every time. } \\
\text { - Conforming to standards } \\
\text { - Conforming to needs of beneficiaries more than he } \\
\text { expected }\end{array}$ & $\begin{array}{c}103 \\
90 \\
86\end{array}$ & $\begin{array}{l}85.8 \\
75.0\end{array}$ & 104 & $\begin{array}{l}86.7 \\
71.7 \\
74.2\end{array}$ & $\begin{array}{l}0.04 \\
0.34\end{array}$ & $\begin{array}{l}0.85 \\
0.56\end{array}$ \\
\hline $\begin{array}{l}\text { - Satisfaction of beneficiaries } \\
\text { - Increase the effectiveness } \\
\text { - Ability to compete } \\
\text { - Reducing costs } \\
\text { - Improving services } \\
\text { - Staff satisfaction }\end{array}$ & $\begin{array}{l}94 \\
87 \\
84 \\
93 \\
97 \\
87\end{array}$ & $\begin{array}{l}78.3 \\
72.5 \\
70.0 \\
77.5 \\
80.8 \\
72.5\end{array}$ & $\begin{array}{l}93 \\
90 \\
87 \\
91 \\
96 \\
86\end{array}$ & $\begin{array}{l}77.5 \\
75.0 \\
72.5 \\
75.8 \\
80.0 \\
71.7\end{array}$ & $\begin{array}{l}0.02 \\
0.19 \\
0.18 \\
0.09 \\
0.03 \\
0.02 \\
\end{array}$ & $\begin{array}{l}0.88 \\
0.66 \\
0.67 \\
0.76 \\
0.87 \\
0.89 \\
\end{array}$ \\
\hline
\end{tabular}

Table (5) shows that there were no statistical significant differences between nurses and physicians' awareness regarding all items of both quality definition and consequences (pvalue>0.05) 
Figure (1): Total awareness of studied nurses and physicians.

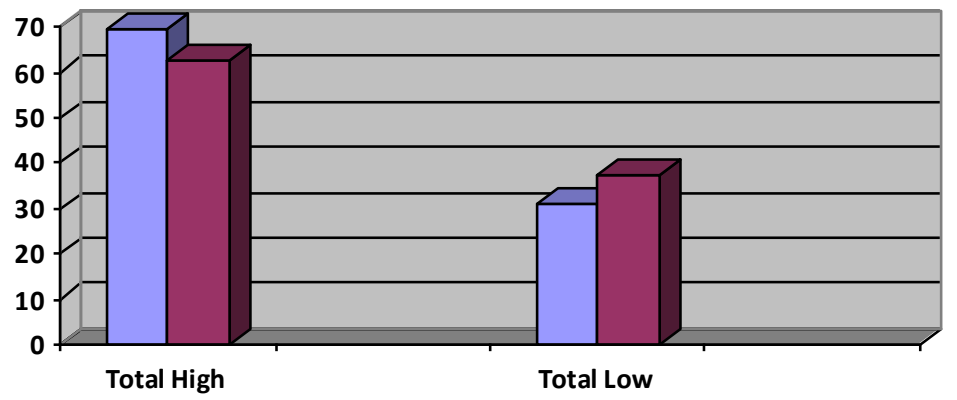

Figure (1) elucidates that the studied nurses had high level of total awareness of quality management system $(69.2 \%)$ more than the physicians $(62.5 \%)$ nevertheless this difference wasn't statistically significant ( $\mathrm{p}$-value $=0.28$ ).

\section{Table (11): Relations between nurses' awareness of}

Table (14): Frequency of studied patients for utilization of various services in the centers during last year $(n=300)$

\begin{tabular}{|l|c|c|c|}
\hline Frequency of visits for: & Range & Mean \pm SD & Median \\
\hline Medical examination & $0-43$ & $5.6 \pm 3.1$ & 3.0 \\
Medications & $0-30$ & $2.9 \pm 2.8$ & 2.0 \\
Vaccination & $0-18$ & $2.2 \pm 2.9$ & 1.0 \\
Maternal care & $0-14$ & $1.9 \pm 2.6$ & 1.0 \\
Child care & $0-17$ & $1.8 \pm 2.7$ & 1.0 \\
Other services & $0-23$ & $1.7 \pm 2.9$ & 0.0 \\
\hline
\end{tabular}

Table (14) reveals that the medical examination service had the higher frequency of patients' visits during the last year with mean $\pm \mathrm{SD}(5.6 \pm 3.1)$ followed by medications and vaccinations services with means $\pm \mathrm{SD}(2.9 \pm 2.8 \& 2.2 \pm 2.9)$ respectively.

Figure (2): Total Patients' Satisfaction Score
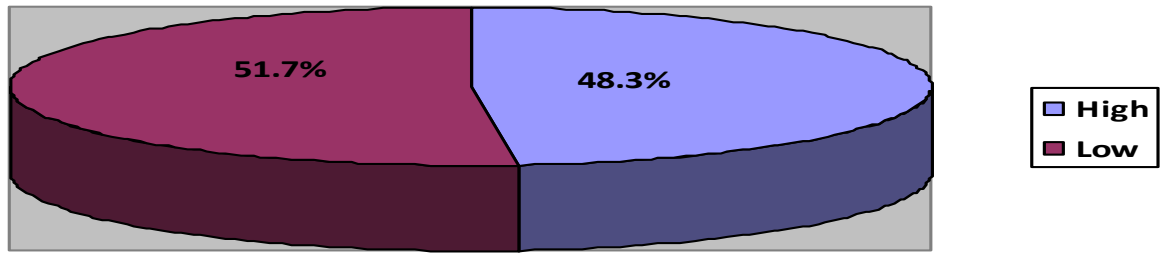

Figure (2) describes that the low ( $<60 \%$ of total score) total patients' satisfaction $(51.7 \%)$ was higher than the high ( $\geq 60 \%$ of total score) total patients' satisfaction $(48.3 \%)$. Although most of the studied family health centers had quality management system as well most of it was accredited 
but still slightly more than half of the patients were dissatisfied with the quality of services and management delivered to them at these centers.

Part (IV): Correlations between healthcare providers' awareness and patients's satisfaction

Table (20): Ecologic correlation between healthcare providers' awareness scores and patients' satisfaction scores

\begin{tabular}{|r|c|c|c|}
\hline \multirow{2}{*}{ Variables } & \multicolumn{3}{|c|}{ Spearman's rank correlation coefficient } \\
\cline { 2 - 4 } & Nurse awareness & Physician awareness & Patient satisfaction \\
\hline Nurse awareness & & & \\
\hline Physician awareness & $0.613^{*}$ & & \\
\hline Patient satisfaction & .035 & .392 & \\
\hline
\end{tabular}

(*) Statistically significant at $\mathrm{p}<0.05$

Table (20) shows the ecologic correlation between healthcare providers' awareness scores and patients' satisfaction at the studied centers. It reveals that there was a positive relationship as the correlation coefficient at ( $\mathrm{p}=0.035<0.05$ ), so the patients' satisfaction was increasing proportionally due to increasing in nurses and physicians' awareness.

Table (21): Correlation between healthcare providers' awareness scores and their characteristics.

\begin{tabular}{|l|c|c|}
\hline \multirow{2}{*}{ Variables } & \multicolumn{2}{|c|}{ Spearman's rank correlation coefficient } \\
\cline { 2 - 3 } & Nurses scores & Physicians scores \\
\hline Age & $.224^{*}$ & -.024 \\
\hline Experience years & $.276^{* *}$ & .082 \\
\hline Qualification & -.166 & -.092 \\
\hline Job position & -.130 & -.071 \\
\hline
\end{tabular}

(*) Statistically significant at $p<0.05$

(**) statistically significant at $p<0.01$

Table (21) shows that the healthcare providers' awareness increased by increasing of nurse's ages and years of experience also the same as the physicians. 
Table (25): Correlation between patients' satisfaction scores and their characteristics

\begin{tabular}{|l|c|c|}
\hline \multirow{2}{*}{ Variables } & \multicolumn{2}{|c|}{ Spearman's rank correlation coefficient } \\
\cline { 2 - 3 } & Patient rights scores & Total satisfaction scores \\
\hline Age & $.349^{* *}$ & $.413^{* *}$ \\
\hline Education & .053 & -.005 \\
\hline Income & $-.127^{*}$ & $-.167^{* *}$ \\
\hline Frequency of visits for: & & .031 \\
\hline Medical examination & .009 & .092 \\
\hline Medications & .073 & .099 \\
\hline Vaccination & .099 & .009 \\
\hline Maternal care & .014 & .083 \\
\hline Child care & .067 & $.314^{* *}$ \\
\hline Other services & $.277^{* *}$ & \\
\hline
\end{tabular}

(*) Statistically significant at $p<0.05$

(**) statistically significant at $p<0.01$

Table (25) shows that there was a higher total satisfaction scores for patients due to higher percentages in their ages and medical services provided to them.

Discussion:

Quality management system is a profound change in family health centers that leads to transformation of its organization, this transformation concerns every actor within the organization, it implies a change in culture, habits and behavior, and it obstruct the sociological hierarchy and power system, setting up quality management that should take into account these obstacles which implies leading the organizations culture and management system is broadly defined as all the procedures explicitly designed to monitor, assess and improve the quality of care (Fathy, 2013).

This study aimed to assess healthcare providers' awareness regarding quality management system and it's relation to patients' satisfaction through assessing the awareness level of healthcare providers regarding quality management system, assessing the level of patients' satisfaction regarding quality of healthcare and finding out the relationship between healthcare providers' awareness and patients' satisfaction.

This finding was consistent with Hyett, (2013) who reported that nurses supposed to have more knowledge and skills, because most nurses have readiness to increase their knowledge. This finding was supported by Hoonakker \& Korunka, (2014) who suggested that inadequate knowledge and performance indicated poor quality of care given. Huston \& Marquis (2014) pointed that an in-service educational program is always needed for updating nurses' knowledge, improving nurses' development and skills also increasing the ability to function purposefully in emergency situation.

This finding was consistent with Fisher, (2011) who reported that attended training courses about quality system are related to the high levels of performance. This training is achieved by seminars, workshops, videotape training programs. Educational consultants are now available to teach process improvement in health care. Also, Alserouri \& Alsofeani, (2015) stated 
that learn and follow standards which are thought to ensure quality care to patients, that management at different levels monitor, supervise and support these actions.

The current study result revealed that there was a highly percentage of female patients used to attend the studied centers in comparable with less percentage of male patients, and those patients whose suffering from chronic diseases attended rarely to studied centers than other patients with regular medication. Also it showed that there were a highly percentage of female patients and a high percentage of ages more than 30 years as well as a higher percentage of marital status "married" and approximately similarities in percentages of education, job and income criteria in studied centers sample.

\section{According to (Muhammad Afzal,}

2014) Patient satisfaction is one of the several ways to evaluate the quality of care, an outcome variable in its own right, and is an indicator of weaknesses in the service. Previous literature showed that satisfaction level can be dependent on many factors other than the quality of service delivery, it may subject to factors like patients' demographics. Among demographic characteristics, age, health status, and race had a consistent, statistically significant effect on satisfaction scores. Some institutional characteristics also showed consistent and significant effect on patient satisfaction score. . .

In the same line Quintana et al., (2014) previous literature showed that older patients tended to have higher satisfaction scores in all respects. Educational levels of patients also found a contributor to patient satisfaction and those with no education or only primary education had higher satisfaction scores. Marital status was also a major contributor towards the satisfaction of patients with healthcare facilities and those married or cohabitating tended to have higher satisfaction scores, but in another study those who were single or divorced had higher satisfaction scores with health care facility. .

Sultana, (2013) also showed gender dependency of patient satisfaction and it was found that males tended to have higher satisfaction scores than females. The literature shows that job status of a person can have effect on satisfaction level but results of some studies revealed that this variable don't have any influence on patient satisfaction.

This finding was also consistent with Raines, (2012) who revealed that good information must be available and must be used in decision making by nurses and physicians to exercise clinical judgment by making sound decisions; clinical judgment can be viewed as critical thinking applied in clinical situations. Judgments are formed after collecting assessment data and examining the relationships among those data.

In the same respect Barry, (2013) described that awareness of decision making is important in the informed healthcare policy, implementation standard and guidelines.

The present study denoted that there was highly statistically significant in awareness regarding both quality dimensions and elements among studied nurses and physicians. This result was in agreement with Furstenberg, (2013) who reported that awareness of dimension of quality help provide specific direction for policymakers and healthcare providers to implement change and improve health care in their centers. Also awareness of quality related to provide services that based on scientific knowledge to all who could benefit and doing the right thing for the right person at the right time. 
The present study revealed that there were statistically significant relations between physicians' awareness and their socio-demographic characteristics as experiences and age. Whereas physicians who had bachelor degree and had 5 to 10 years experiences, and attending quality programs were satisfied about their jobs and had a high degree of quality awareness. This was consistent with Walinga, (2011) who explained that when the physicians more educated and have experiences become more wise and aware.

In the same line Janasz et al., (2013) found that individuals high in selfawareness seek feedback, learn from their mistakes, and understand when to work with others who have complementary strengths. This understanding of oneself brings about greater understanding of others, making these individuals appear trustworthy and competent.

The present study result revealed that the highest utilized service by patients in the study centers was more focused on the medical examination, followed by medication, vaccinations, maternity and child care. This confirmed that the highest patients' satisfaction for utilizing these healthcare services compared to the other services which were less demand for use.

The current study result revealed that there was a positive Ecologic correlation between healthcare providers' awareness score and patients' satisfaction total score in studied centers, so the patients' satisfaction will be increased proportionally due to the increasing of nurse and physicians' awareness. This is explaining why there was an increasing of the awareness of healthcare providers in the health centers which have quality programs which lead to an increasing in patients' satisfaction regarding healthcare provided to them in these centers.
The result revealed that the healthcare providers' awareness will be increased due to the increasing of nurse's ages and experience years also same as to the physicians. Also job qualification affected the awareness as it enhanced the qualification and enhanced for awareness.

This finding was consistent with Reason, (2010) who showed that medical errors that occur either do or do not harm patients and reflect numerous problems in the system, such as a culture not driven toward safety and the presence of unfavorable working conditions for nurses and this reflects the doctors' awareness of the quality system, leading to a lack of awareness indicators.

\section{Conclusion:}

In the light of the current study findings it can be concluded that:

- The studied nurses had high level of total awareness of quality management system more than the physicians; nevertheless the difference wasn't statistically significant.

- Years of experience, attendance training courses in quality, and sharing in quality programs had a significant impact on the total nurses' awareness.

- Administrative job, nursing qualification, job position, specialty, and age of nurses hadn't significant impact on the total nurses' awareness.

- Increasing of healthcare providers' awareness regarding quality management system had a significant impact on increasing the quality of healthcare services which 
in turn resulting in increasing of patients' satisfaction.

- Although all the studied family health centers had quality management system but still slightly more than half of the patients were dissatisfied with the quality of services and management delivered to them at these centers.

\section{Recommendations:}

\section{recommended that:}

In the light of study findings, it is

Increase awareness of health care providers about quality system through Conducting quality training programs and educational training.

- Activate the communication system between health care providers and patients in the studied centers.

- Improving the quality of health care provided to patients in the studied centers.

- Developing a climate of quality in health services by setting the vision, encouraging and supporting initiatives at district and facility level.

- Suggestions and complaints of patients should be Taken into consideration to improve quality services and increase patient satisfaction.

Motivating the health care providers to improve their performance and work better to improve the quality of health service provided and achieving high satisfaction.

- Speed up re-accreditation of the studied centers to increase the level of awareness of health care providers and quality of services according to standards.

\section{Suggested researches:}

- Conducting a study on quality of health services improvement in family health centers and it's compliance with Egyptian Accreditation Standards.

- Implementation of the quality management system and its relation to the job satisfaction for the employees in the health field.

- Conducting a study on health care providers' awareness regarding quality management system and its relation to quality of their performance.

\section{References}

Alserouri, A., \& Alsofeani, (2015): Improving quality and performance, $1^{\text {st }}$ ed., Maple vail-Binghamton, London, pp: 3-4

Barry, J., (2013): The impact of systems redesign on staff, patient, and financial outcomes. Journal of Nursing Administration, 30(2), 77-89.

Fathy, M., (2013): Health Care providers' awareness about quality system and its relation to quality of their performance at Maternal and Child Health centers. P1,p22.p25:60. 
Fisher, K., (2011): Leading self-directed work teams: A guide to developing new team leadership skills. New York: McGraw-Hill. PP. 122-148.

Furstenberg, F.F., (2013): Prescribing as an Index to Quality of Medical Care: A Study of the Baltimore City Medical Care Program. American Journal of Public Health. 43:1299-1309.

Hoonakker, P. \& Korunka, C. (2014): Information and communication technology and quality of working life: Backgrounds, facts, and figures. In Korunka \& Hoonakker (Eds.), The Impact of ICT on Quality of Working Life. Springer Press: Dordecht, The Netherlands. pp. 8-26.

Huston, C., \& Marquis, B. (2014): leadership role and management functions in nursing: Theory and application, (7th Ed), Wolters Kluwer Health / Lippin cott Williams \& Wilkins, China, pp.543-550.

Hyett, N. (2013): Current incidence of prematurely, Nursing Prenatal Journal, 4(5): 12-25.

Jack, D., \& Larry, V., (2004): client perception of the quality of primary care services in Afghanistan; International journal for quality in health care; 20 (9): 384-391

Janasz, S.D., Wood, G., Gottschalk, L., Dowd, K., and Schneider, B. (2013): Interpersonal Skills in Organisations. Boston: McGraw-Hill. Available at: http://trove.nla.gov.au/ work $/ 20858803$ ? selectedversion $=$ NBD40 $\underline{203068}$

Join Commission on Accreditation of health care (JACHO), (2005): Dimensions of quality care according to which quality in any health care setting organizations. Available at http:www.jcaho.org\PMS dimension. Quality care/index.htm Accessed at November; 2010.

Kobylanski, L., Kish, L, Survey, S., Janet, L., (2011): " The Role of Customer Satisfaction in the Quality Management Systems: A Cross cultural Study. Pak J Med Sci 2009;25:439-42.

Legido, H., (2008): Assuring the quality of care the European union A case For action, $1^{\text {st }}$ ed., European observatory on health system and policies comp., United King Dom, p: 3.

Lippincott, W., \& Wilkins, W., (2011): The Official Publication of the Infusion Nurses Society. Journal of Infection Nursing. 77(16): 1503-1582.

Loraine, A., (2011): About Total Quality Management, available at: http://www.ehow.com/about_4740144_to talqualitymanagement.htm1zz1BJFfe1bh, available on 5-8-2011.

Muhammad Afzal, (2014): Effect of demographic characteristics on patient's satisfaction with health care facility; Department of Community Medicine, Islamabad Medical and Dental College, February 06, 2014 Islamabad - Pakistan. Available at http://applications. emro.who.int/imemrf/ J_Postgrad Med_Inst/J_Postgrad_Med_Inst_2014_28 2__154_160.pdfj

Quintana, J., Gonzalez, N., Bilbao, A., Aizpuru, F., Escobar, A., Esteban, C., (2014): Predictors of patient satisfaction with hospital health care. BMC Health Serv Res; pp 6:102. available at http://applications. emro.who.int/ imemrf/ J_Postgrad_Med Inst/J_Postgrad Med_Inst_2014_28_2_154_160.pdf . 
Raines, M. L., (2012): Ethical decision making in nurses: Relationships among moral reasoning, coping style, and ethics stress.

Reason J. (2010): The contribution of latent human failures to the breakdown of complex systems. Philosophical Transactions of the Royal Society of London, Series B. 2010;327:475-84.

Sultana, A., Riaz, R., Rehman, A., Sabir, S.. (2013): Patient satisfaction in two tertiary care hospitals of Rawalpindi. J Rawal Med Coll;13:41-3.

Swayne, L.E., Duncan, W.J., \& Ginter, P.M., (2014): Strategic management of health care organizations, $\left(5^{\text {th }}\right.$ Ed.). Black well publishing co. Britain, P.349.

Sylvester, J., \& Fathy, J., (2013): Health Care providers' awareness about quality system and its relation to quality of their performance at Maternal and Child Health centers, Master, Thesis Benha faculty of nursing, Benha University, P1.

Walinga, J., Cunningham, J. B., \& MacGregor, J., N. (2011): Training insight problem solving through focus on barriers and assumptions. The Journal of Creative Behavior; 45(1):47-58.

Waltz, C.F., (2010): Measurement in nursing and health search, 4th ed., Springer publishing co: USA, P: 47.

Wensley, (2001) \& Mohammed. A, (2012): Evaluating the implementation of quality management system and its relation to patient satisfaction at Benha university hospitals, Master, Thesis Benha faculty of nursing, Benha University, pp5. 